\title{
Transgenic Plants and Biosafety: Science, Misconceptions and Public Perceptions
}

BioTechniques 29:832-843 (October 2000)

\section{Neal Stewart, Jr., Harold A. Richards, IV and Matthew D. Halfhill \\ University of North Carolina, Greensboro, NC, USA}

\begin{abstract}
One usually thinks of plant biology as a non-controversial topic, but the concerns raised over the biosafety of genetically modified $(G M)$ plants have reached disproportionate levels relative to the actual risks. While the technology of changing the genome of plants has been gradually refined and increasingly implemented, the commercialization of GM crops has exploded. Today's commercialized transgenic plants have been produced using Agrobacterium tumefaciens-mediated transformation or gene gunmediated transformation. Recently, incremental improvements of biotechnologies, such as the use of green fluorescent protein (GFP) as a selectable marker, have been developed. Non-transformation genetic modification technologies such as chimeraplasty will be increasingly used to more precisely modify germplasm. In spite of the increasing knowledge about genetic modification of plants, concerns over ecological and food biosafety have escalated beyond scientific rationality. While several risks associated with GM crops and foods have been identified, the popular press, spurred by colorful protest groups, has left the general public with a sense of imminent danger. Reviewed here are the risks that are currently under research. Ecological biosafety research has identified potential risks associated with certain crop/transgene combinations, such as intra- and interspecific transgene flow, persistence and the consequences of transgenes in unintended hosts. Resistance management
\end{abstract}

strategies for insect resistance transgenes and non-target effects of these genes have also been studied. Food biosafety research has focused on transgenic product toxicity and allergenicity. However, an estimated 3.5 $' 10^{12}$ transgenic plants have been grown in the U.S. in the past 12 years, with over two trillion being grown in 1999 and 2000 alone. These large numbers and the absence of any negative reports of compromised biosafety indicate that genetic modification by biotechnology poses no immediate or significant risks and that resulting food products from GM crops are as safe as foods from conventional varieties. We are increasingly convinced that scientists have a duty to conduct objective research and to effectively communicate the results-especially those pertaining to the relative risks and potential benefits-to scientists first and then to the public. All stakeholders in the technology need more effective dialogues to better understand risks and benefits of adopting or not adopting agricultural biotechnologies.

\section{THE ANATOMY OF A CONTROVERSY}

Until 1999, the controversy surrounding genetically modified (GM) crops existed obscurely among those in the environmental movement-at least in the United States. Until that time, the production and commercialization of GM crops in this country and others were quietly progressing to the point that close to half of soybean and cotton and over one-third of corn and canola (a genetic variation of rape seed) in the U.S. was GM (Figure 1). Since 1992, the USDA has deregulated 60 transgenic crop varieties for commercial field release (Animal and Plant Health Inspection Service Permits April 2000: http://www.isb.vt.edu/) (Figure 2), and farmers have adopted GM varieties at record speed.

During the same period, academic and government scientists were actively performing experiments and publishing research on plant transformation and biosafety. The silence on all fronts was suddenly broken in 1998 by publicity surrounding scientific research findings. The first blow came when Arpad Pusztai, an immunologist at the Rowett Research Institute in Aberdeen, Scotland, appeared on UK television to announce that GM potatoes transgenic for snow drop lectin were toxic to rats and com promised their immune systems. His television interview focused media attention on GM crops and was the catalyst for Europe's rising furor against such crops and food. By the time his study was published (11), the controversy had jumped to the U.S. Besides the conclusion from the lectin study that the plant transformation process itself caused food to be toxic, a U.S. paper was published in the British journal $\mathrm{Na}$ ture in May 1999 (42). Here, the authors reported that pollen from corn transgenic with an insect resistance-coding gene from Bacillus thuringiensis (Bt) was hazardous to the Monarch butterfly. In various forums, environmental activists reenacted the death of Monarchs approaching an ear of corn that also happened to have a giant $\mathrm{X}$ on it.

On the surface, such displays can be viewed as sophomoric, but the impact of detractors to agricultural biotechnology has been widespread. A near trade war started between the European Union and the U.S. when companies such as Heinz and Gerber banished ingredients from GM crops in their products and the Greenpeace organization 
held a major campaign to persuade U.S. food companies such as Kellogg's to stop using genetically modified organisms (GMOs) in their products. The Monarch butterfly study did serve to illustrate that perhaps the risks to nontarget insects had not been thoroughly studied before the commercial release of transgenic plants and perhaps other detrimental side effects would be observed during the lifetime of a transgenic product.

Some will argue that a misrepresentation of science is at the root of the GM controversy, perhaps even that scientists themselves have played an active role in its explosive growth. Others will say that research on the risks and benefits of biotechnology were not presented to the public in a manner that allowed for informed conclusions to be drawn. Of course, this is not just a scientific issue, and it is quite complicated. Our purpose here is to focus on the science that underlies plant transformation and genetic modification, the ecology of transgenic plants and the biosafety of GM food-essentially, the science behind the controversy.

\section{PLANT TRANSFORMATION}

\section{Plant Tissue Culture}

Plant transformation generally relies on the introduction of plasmid constructs or segments of plasmid constructs into the genome of a plant cell. Entire transgenic plants must be regenerated from transformed cells, not a trivial task. Many plant cells are totipotent, that is, they are able to regenerate an entire plant from a single cell. How ever, tissue culture is slow, laborious, requires special skills and has the propensity to cause mutations in the DNA within plant cells. Some crops such as soybean and sunflower have complex tissue-culture systems. In a molecular breeding sense, premier varieties that have the most desirable innate traits are seldom the most amenable to tissue culture. That said, commercial GM crops have largely been produced using plant-transformation systems using tissue culture. Here, we will briefly review the evolution of transformation technology and speculate on how inno- vations might impact the GM crop landscape. A more complete, recent review is available (21).

\section{Conventional Transformation Technologies}

The first plants were transformed in the mid-1980s using Agrobacterium mediated transformation (28), a method that exploits the natural propensity of the crown gall disease-causing agent, Agrobacterium tumefaciens, to transfer genes into a plant genome. Many plant species including tobacco and Arabidopsis can be routinely transformed using this method. Most crop plants are not amenable to Agrobacterium for routine transformation (20). In 1987, this problem was addressed by the invention of the gene gun. Also known as microprojectile bombardment $(33,34)$, this invention uses micrometer-sized particles coated with DNA that are accelerated to randomly pierce plant cells. The scope of this method is broader than that of Agrobacteriumbut is less precise in its transgene integration patterns (12). Nearly all of the commercial transgenic plants in current existence-and most of those that will be produced in the next few yearswill all be produced using Agrobacteri$u m$ - or gene gun-mediated transforma-

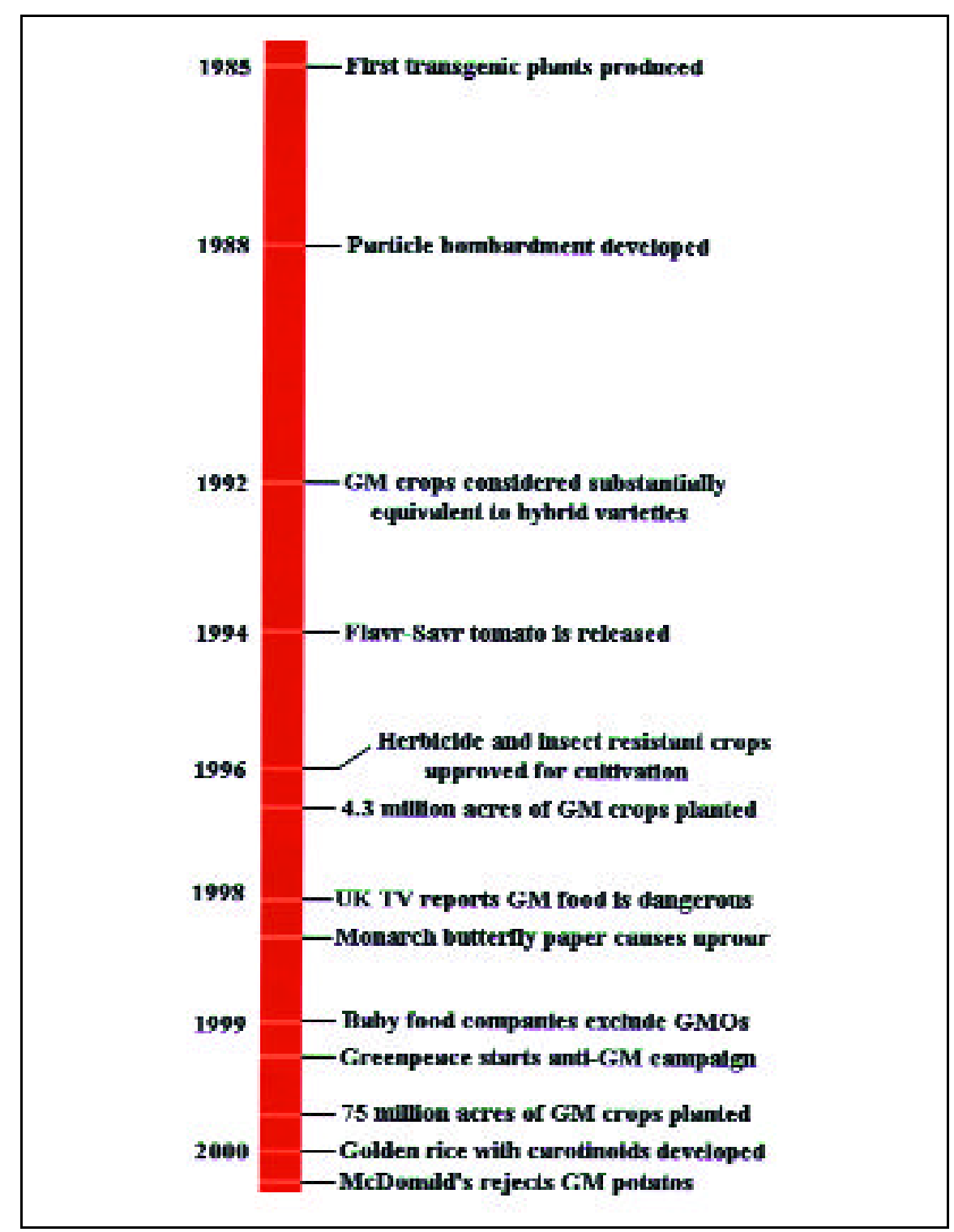

Figure 1. Timeline of important events in the use of GM crops. 
tion of cells, followed by regeneration using tissue culture.

\section{New Technologies for Genetic Modification}

Tissue culture-free transformation. Beginning in the late 1980 s, successful experiments were performed to diminish the need for tissue culture in plant transformation. In one application, a novel gene gun was used to bombard genes into soybean seedling meristems $(6,44)$. After bombardment, the meristems were placed on cytokinin-containing medium to obtain multiple shoot formation. This method did not use any selectable marker, but rather the stable transformation that was detected using the presence of $b$-glucuronidase (GUS) in putatively transformed tissues. How ever, this system required destructive tissue sampling and an expensive substrate (X-GLUC) to detect gene expression and transgenic status (29).

Vacuum infiltration of Arabidopsis was developed as the first method to bypass tissue culture entirely (3). Here, the developing floral meristems/flowers are placed in an Agrobacterium solution under vacuum, and germ cells are transformed. The plant is grown out and allowed to set seed. Potentially, each new seed that is collected represents an independent transformant. This method has been used to produce large numbers of

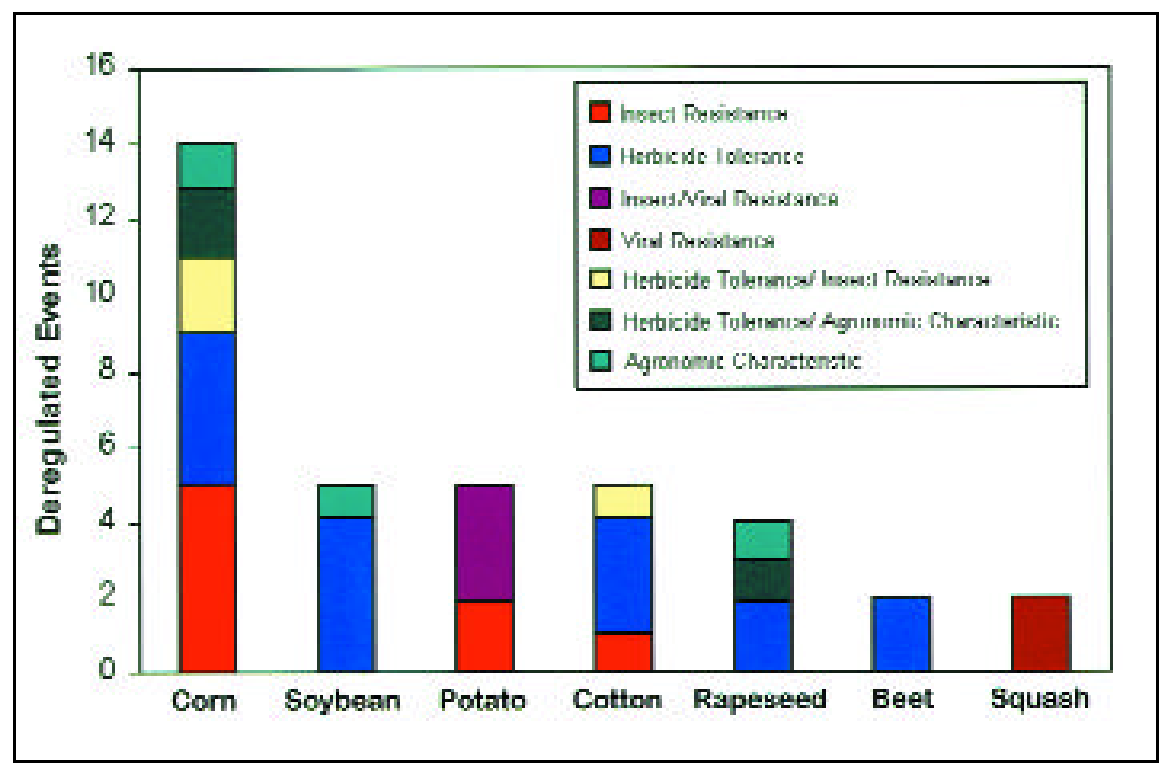

Figure 2. Deregulated transgenic events for crop species with two or more deregulated phenotypes, as of April 1999 (www.isb.vt.com).
T-DNA insertion mutagenized Arabidopsis plants (36). More recently, the vacuum step has been found unnecessary and that simply dipping flowers in Agrobacterium solution is sufficient to transform cells (7). While there have been attempts to use this methodology on other plants species, there are no published successes to date.

\section{Visual Selection}

When cells are transformed, they are usually selected using antibiotics or an herbicide that kills untransformed cells (negative selection). Research has made strides toward developing positive selection systems. For example, cells that are transformed with a gene allowing them to metabolize mannose $(30,66)$ or to be more responsive to cytokinin (38) allow transformation to take place in the absence of antibiotic or herbicide resistance genes. Another approach would be a selection based on a visible marker gene, such as the one encoding the green fluorescent protein (GFP), which has the unique characteristic of fluorescing green when exposed to UV or blue light. Transformed cells can be visibly selected on the basis of green fluorescence (Figure 3). Such an approach also increases the efficiency of transformation (16) and might aid in tissue culture-free transformation. For example, by using the meristem method described earlier in soybean, it might be possible to process more samples and troubleshoot the methodology more rapidly. Being able to see in real time which cells and tissues are transformed could enable faster and more efficient transformation technologies to be developed.

\section{Chimeraplasty}

Plant transformation technologies have become more efficient. Such technologies have enabled many transgenic plants to be produced and have allowed the subsequent commercialization of a wide variety of transgenic crops. A technology called chimeraplasty has been developed that allows precise genetic modification to a plant without transformation. Point or frameshift mutations can be introduced using chimeric DNA/RNA (8). This approach has been successful on tobacco and corn, and holds great promise for making precise but small genomic changes in virtually any crop $(4,69)$. For example, chimeraplasty could be used to frameshift a gene coding for a known allergen in peanut or other allergen-ladened crops and therefore halt its expression. Such a genetic modification would be both precise and a substantial improvement in food safety, and could possibly be accomplished using such a technique.

Improved methods such as transformation and chimeraplasty offer great potential to accelerate the development of genetic modification. While some fear that such technology is moving too quickly, scientists are beginning to understand precise genetic modification, and the results are promising. Great strides have been made in better understanding how genes are integrated (20, $35,52)$ and silenced $(31,43,63,65)$. Scientific knowledge will greatly assist in the precision and predictability of transgene expression in plants. Soon, the metabolic engineering of crops will be accomplished to make significant changes in crop-output traits, such as altered physiology resulting in more nutritious food, alternative fuels and facilitated pharmaceutical delivery. One recent success has been the creation of "golden rice" that is rich in vitamin A (68). In the next 20 years, we believe most row crops will be genetically modified, and perhaps nearly all non-wild plants will 
be genetically modified by the year 2100. The ubiquity of the technology does force one to consider the safety and risks of its wide implementation.

\section{ENVIRONMENTAL AND HEALTH BIOSAFETY}

The risk assessment of agricultural and food technologies is not a new concept. Each innovation in food production has come with its own set of potential risks. These have ranged from increased pesticide exposure in conventional agriculture to higher pathogen exposure from organic farming. The risks associated with GMOs are similar to those of crop hybridization, the keystone of the first green revolution. Conventional hybridization techniques result in new varieties of crops that contain hundreds to thousands of introduced genes. The new genes can have multiple and unexpected effects on crop ecology, physiology and food value. By contrast, GM consists of the transfer of one to several genes, resulting in more predictable and easily studied effects. Therefore, a priori, genetic modification should result in fewer unintended risks, but this is not the message the general public receives.

Any attempt to create a better crop plant will be accompanied by potential consequences. Risk assessments of biotechnology do consider potential effects to environmental and human health. In general, these risk assessments have been an order of magnitude more strin- gent than for conventionally produced crops and food. Ecological concerns that are currently debated are increased invasiveness and volunteerism (an agriculture problem where uncollected seeds from the last year's crop germinate and grow within the current crop), both intra- and interspecific hybridization, damage to non-target organisms and resistance management. Assessing the biosafety of GM food has relied on the doctrine of substantial equivalence, that is, GM food is as safe as its genetic precursor, which is generally regarded as safe. A snapshot of the current debate is available (12). Since GM food has been extensively tested for increased toxicity and allergenicity, the key is to determine the importance of the risks as weighed against the benefits.

\section{ECOLOGICAL BIOSAFETY}

\section{Increased Invasiveness and Volunteerism of Transgenic Crops}

As new genes are discovered and used by the biotechnology industry, crops will have suites of new abilities and will be grown in new geographic areas. In the case of crops such as alfalfa (Medicago sativa), canola (Brassica napus and Brassica rapa) sunflower (Helianthus annuus) and rice (Oryza sativa) that have some weed-like characteristics, some have argued that their contained transgenic and novel traits could allow the crop itself to become

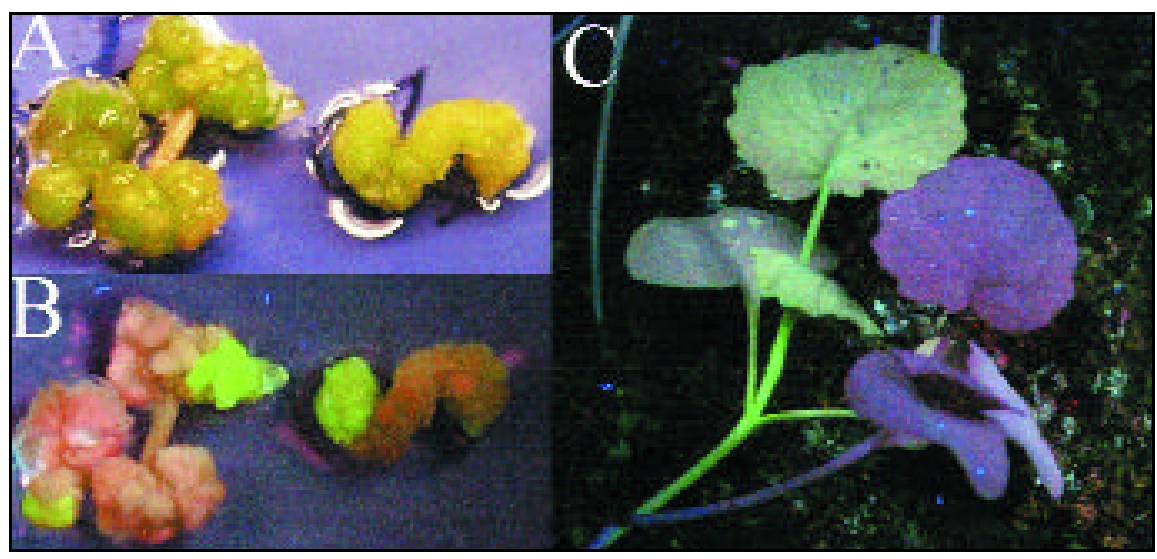

Figure 3. GFP selection of transgenic callus and GFP fluorescence of whole plants. (A) Canola hypocotyls five weeks after incubation with $A$. tumefaciens containing a GFP gene linked to a Bt gene under white light; (B) the same canola sections under UV light. (C) GFP/Bt canola (left) and non-transgenic canola (right) pictured under UV light. weedier and invasive $(53,54)$. This would not be a problem in many crops that are highly domesticated and exotic to the regions in which they are grown (such as soybean and corn in the U.S. and Canada) because they do not have the traits needed to allow survival outside agriculture (64). Canola has been genetically modified with at least three distinct herbicide resistance genes (two from transgenesis and one from mutagenesis), and volunteers of these varieties could become a nuisance in agriculture by requiring other herbicides for their control (64). Special regulatory efforts have been applied to certain transgenic crops that have the potential for increased invasiveness and damaging volunteerism.

\section{Intraspecific Hybridization}

Intraspecific hybridization can occur when transgenic crops are grown in close proximity to non-transgenic varieties. The agricultural practice of saving seed from the previous year's harvest allows transgenic material to be unintentionally persistent. Corn and other grain crops that are wind-pollinated have the potential to pass genes to adjacent conspecifics (of the same species), whether the crop is GM or a conventional variety. This is a problem for organic farmers who must ensure that their products are not GM but who can suffer economic losses if transgenic material is found in their harvests. Fitness-enhancing genes can be dispersed within the same species with no hybridization barrier, which can lead to slightly higher numbers of GM individuals than are expected by regulatory agencies. It is possible that transgenic crops can rapidly accumulate fitnessenhancing traits (transgene stacking) that could lead to new and potential unintended problems.

\section{Interspecific Hybridization and Transgene Persistence}

Hybridization between closely related species can be a mode of transgene flow directly into wild populations $(10,53)$. Crop plants with weedy, wild relatives are of particular concern. If expressed in the genetic background of a weed species, a transgene can 
increase the fitness of the weed in nature. In a worst-case but perhaps most unlikely scenario, the weed could become more invasive and competitive and in a relatively short time could cause damage to natural ecosystems.

Interspecific hybridization depends on several circumstances to allow gene flow between related species. The crop must have some naturally occurring wild relatives growing near cultivation. Since corn and soybean crops have no relatives in the U.S. and Canada, they represent no risk of interspecific gene flow. Alfalfa, Brassica crops and rice are examples of crop species that do have wild relatives near cultivation $(53,64)$, and these species complexes should be the focus for future gene flow studies. The two species must share a degree of sexual compatibility, and distantly related species sometimes share enough genome homology to produce viable progeny (56). The species must occur sympatrically or at close enough distances to allow the transfer of viable pollen. Flowering time must occur concurrently for the two species to be fertile at similar periods throughout the year. Many weeds have complex patterns of dormancy, asynchronous germination and germination signaling, which have been lost in crops by artificial selection $(1,41)$.

The variable homology of the genomes between related species leads to a wide range of possibilities for the rate of introgression of a transgene, or any other gene, after the $\mathrm{F}_{1}$ hybrid generation. Meiotic abnormalities caused by the distant relation between parental genomes can lead to decreased rates of introgression into new genotypes (32, 56). Chromosomes can be lost or disrupted as a result of unequal pairing at metaphase, which results in higher rates of infertility and decreased rates of seed production. Recombination, an important process in the incorporation of foreign DNA, is diminished in the unstable chromosome configurations of hybrids from distant relatives. In contrast, hybrids produced by closely related species have been shown to combine fitness indices (seed production, pollen fertility, biomass, etc.) that parallel the parental species $(24,25,46)$. In this situation, the hybridization barrier between these species can be quite low, and the introgression of a transgene is likely. The reproductive fitness of interspecific hybrids affects the ability of a transgene to be lost in the genetic background of a wild relative.

The possibility for increased fitness of transgenic hybrids and backcrosses depends on the nature of the transgene and the environment (10). For example, weeds containing a transgene that confers resistance to an herbicide would be a nuisance to agriculture but would have little effect in a non-agricultural 
environment where the herbicide is absent. In contrast, an insecticidal $\mathrm{Bt}$ transgene in a weed host could alter natural ecology by giving transgenic weeds a selective advantage as the result of natural insect pressure (60) if that specific insect was critical to limiting the survival of the weed. Transgenes that provide fitness-enhancing characteristics under natural conditions have the greatest potential to disrupt the balance of established ecosystems.

How much weed fitness increase from transgenes should be tolerated? Ellstrand et al. (10) have suggested a threshold of $5 \%$ fitness increase for practical purposes; at that point, they suggest significant economic damage might occur to outweigh potential benefits from the transgenic crop.

Transgenic interspecific hybrids have been produced involving transgenic canola modified with herbicide resistance genes with wild $B$. rapa (46,
47). Following one backcross generation, many of the progeny were morphologically and cytologically similar to the B. rapa parent (46). After successive backcrosses into the weedy parent, it was found that, as expected, up to $50 \%$ of the subsequent BC3 and BC4 hybrids had resistance to the herbicide (46). These results illustrate that a transgene can be passed between species and expressed in successive generations.

\section{Effects to Non-Target Organisms}

Transgenic crops that express insecticidal transgenes to control agricultural pests may also affect non-target organisms $(26,42,55)$. Three studies using corn transformed with a Bt-insecticidal transgene have generated evidence of possible non-target effects. Lacewings (Chrystoperla carnea), an insect predator, suffered from higher mortality rates by feeding on European corn borer (Ostrinia nubilalis) reared on Bt corn, compared to corn borers raised on isogenic (non-Bt-producing) plants (26). However, this was a laboratory study. It would seem a low probability for lacewings to be exposed to European corn borers that have ingested Bt toxin in the field.

In another study, Monarch butterfly larvae (Danaus plexippus) that consumed milkweed (Asclepias curassavica) leaves dusted with Bt-containing corn pollen had decreased feeding, growth and survival rates, compared to larvae that consumed leaves with nontransgenic corn pollen (42). The authors concluded that Bt corn posed a danger to non-target monarch populations that feed on milkweed near Bt cornfields. Several independent authors have questioned the validity of this paper, saying that the methods of the study were not reproducible, the non-choice-based feeding strategy for the larvae was inap- 
propriate and the levels of pollen used were artificially high $(5,27,48)$.

More recently, field experiments have shown that Bt corn has no effects on swallowtail butterflies (67). GM Bt corn was shown to exude active Bt toxin from the roots that could potentially accumulate in the soil (55). In this experiment, transgenic corn was grown in an agar medium, and protein extracted from the medium was fed to tobacco hornworm (Manduca sexta) larvae. These larvae suffered higher mortality rates than larvae fed on non-Bt corn protein extracts. However, under more realistic conditions with soil, others have shown rapid degradation of plantexpressed Bt proteins that were comparable to the rate of degradation of $\mathrm{Bt}$ proteins in microbial products $(50,51$, 59). Clearly, further analysis will be necessary on non-target effects caused by genetically modified crops. However, such research needs to be placed in a context relevant to current practices in agricultural systems.

Possible deleterious side effects must be weighed against the positive effects of an insect control regime that uses insecticidal transgenic plants. The decreased use of broad-spectrum insecticides benefits both human and nontarget insect populations. For example, Bt cotton requires three or fewer insecticide treatments per year. This is a dramatic reduction compared with the 5-12 insecticide sprays needed to control pests in non-transgenic cotton fields (58). It has been recently reported that growing Bt cotton reduced pesticide use by over $900000 \mathrm{~kg}$ during 1997 (17). The overall reduction of pesticide use results in more profits for the farmer and fewer chemicals added to the environment. Insect biodiversity could also be enhanced by the reduction of broad-spectrum insecticides and would allow natural predator-versusprey interactions to occur, enhancing pest control. Insect behavior studies that use choice feeding experiments have shown that a parasitic wasp (Cotesia plutellae) preferentially selected canola leaves damaged by the Bt-resistant diamondback moth (Plutella $z y$ lostella) (57). This wasp experienced no reduced reproductive success as the result of Bt toxicity when it attacked Bt-resistant larvae and could help constrain the spread of Bt-resistant pests through natural predation. The use of fewer insecticides in a pest-control regime for transgenic crops offers advantages to both the environment and the safety of farm workers.

\section{Resistance Management}

Resistance to transgenic proteins by insect pests could limit the duration that an insecticidal transgenic variety can be feasibly grown. The diamondback moth, an important pest to Brassica crops worldwide, was the first documented pest to develop resistance to $\mathrm{Bt}$ toxins applied as microbial formulations in open-field populations (61). Recent documentation shows that $\mathrm{Bt}$ resistance has arisen in at least two independent recessive loci with different modes of action (62). To this point, no dominantly inherited $\mathrm{Bt}$ resistance genes have been documented, but this finding would severely limit the effectiveness of future Bt crops. Various resistance management strategies have been proposed to delay the onset of resistance, with deployment of a high expressing transgenic event coupled with a non-transgenic refuge (58) being the most commonly used method. The refuge allows Bt-susceptible pests to survive on the non-transgenic material and mate with Bt-resistant individuals. The goal of this strategy is to keep the recessive $\mathrm{Bt}$ resistance genes at low levels in the target populations and thus limit the rate at which the entire population will acquire Bt resistance. The effectiveness of this strategy depends on the refuge size, refuge design (mixed with transgenics or separate), rate of spraying the refuge with pesticides and the rate of migration of insect pests (58). These factors must be analyzed to ensure that acquired resistance will not limit the use of this potentially beneficial technology.

\section{FOOD BIOSAFETY}

\section{Toxicity}

Any compound entering the food supply is subject to specific scrutiny for food safety. For example, a potentially toxic transgenic product such as Bt toxin must pass the same standards for safety as are applied to any biochemical pesticide product. Exceptions to this type of testing occur when the gene product expressed in transgenic plants is substantially equivalent to an existing compound in the food supply. Exam ples of this would include expression of normal dietary products like vitamins A and E. However, these would have to be tested for bioavailability and for any unexpected effects that occurred during the transformation process, for exam ple, assessing for substantial equivalence to conventional crop varieties.

Testing for toxicity of food becomes necessary when a plant is overproducing innate compounds or when the transgene product has a known level of toxicity. An example of one of these gene products that would require testing is plant pathogenesis-related proteins (14). This class of proteins is desirable for overexpression because they typically result in one or more forms of pest or disease resistance. However, because these compounds are natural 
antibiological agents, tests are needed to demonstrate safety for human consumption. Tests for toxicity must also be conducted for proteins that are not found in the human diet. GFP has a number of potential uses, from transgene tracking to stress indication (39), but for these applications to be realized, GFP will enter the food supply, which requires that its potential toxicity be determined (Figure 3).

Some scientists have argued that protein products are not the only potential source of toxicity in transgenic plants. They hypothesize that secondary, pleiotropic or mutagenic effects resulting from gene expression or integration could cause unforeseen hazards, including toxicity and limited nutrient availability (9). These issues are addressed during the assessment of substantial equivalence for each product.

The study that initiated the European backlash against GM foods was communicated in an interview granted by Arpad Pusztai on British television. Experimental evidence for this phenomenon (11) was published later. Researchers fed rats either wild-type, wild-type spiked with lectin or transgenic potatoes expressing the lectin protein. Lectins are of commercial interest because of their pesticidal properties. Scientists reported that only the transgenic potato-fed group experienced intestinal damage; they concluded that the genetic transformation process itself caused the observed com plications. Among other points, this study has been heavily criticized for its lack of a control group being fed transgenic potatoes that did not express the lectin gene and the study's lack of balanced diets (37). The diets were not balanced for protein or other components, which could explain the observed results.

Other researchers have reported results that contradict the Ewan and Pusztai (11) conclusions. Hashimoto et al. (23) engineered potatoes that overexpressed soybean glycinins to elevate the content of leucine, lysine and threonine. They hypothesized that increased intake of these amino acids will result in low ered serum cholesterol. In their analysis, they fed rats either a control diet, control diet with non-transgenic potatoes or a control diet with one of two transgenic lines of potatoes. They found no significant differences in the health status of the rats in each respective group. If genetic manipulation itself were responsible for health complications, as has been suggested, then the transgenic potatofed groups would have experienced some measurable complication. Interestingly, the serum cholesterol of the rats did not change, but the authors note that the expected nutritional benefit should only be seen in animals with high levels of serum cholesterol. Similar results were obtained when toxicity studies were conducted on herbicide-resistant soybeans $(19,22)$.

\section{Allergenicity}

Another concern related to food safety is the potential for GM food to introduce allergens into the food supply. If the allergenicity of the com pound is known, then the process of evaluation is simplified. Gene products that are not allergenic normally will not suddenly become allergenic when expressed in a transgenic plant. For instance, because no known case of allergies to plant ferritin exists, transgenic iron-enriched rice (18) poses no allergenicity risk. If the gene product is a known allergen, then it will also be an allergen in a transgenic plant. As an example, when a Brazil nut albumin was expressed in soybean to boost methionine content, it was found that serum from Brazil nut-allergic subjects reacted with the transgenic soybean extracts (49). Therefore, people with an allergy to Brazil nuts would now also be allergic to that line of soybeans, even though they were not allergic to native soybean before. For safety's sake, this line of soybean was not commercialized.

Allergenicity assessment is considerably more complicated when the allergenicity of a transgenic protein is unknown. GFP is once again a good example. Although there are no known allergies to GFP, might it induce allergies when people begin to routinely ingest GM foods that express GFP? Even though over 200 food allergens have been identified and sequenced (15), no common motif or consensus sequence has been discovered. However, a generalized protocol has been developed to examine potential allergenicity that is based on physico-chemical properties of known allergens (45).

Most known food allergens are stable to digestion (2). Therefore, testing a protein's stability during the digestive process is one way to identify potential allergens. If a protein is degraded in the stomach and small intestines, then it is unlikely to reach immune cells to cause a hypersensitivity response. Stable proteins should be examined further. These experiments can be coupled with a comparison of sequence similarity to known allergens. Novel proteins with a significant sequence similarity can be tested for reactivity with serum from subjects who are allergic to the homologous allergen. Although these tests may not be comprehensive in identifying potential allergenicity, the limited variety of source foods suggests that the vast majority of transgene proteins will be safe for consumption (40). Over $90 \%$ of the people who have food allergies are allergic to one or more of the following foods: cow's milk, wheat, nuts, legumes, eggs or seafoods.

\section{CONCLUSIONS}

The Biotechnology Industry Organization (BIO) estimates that 76.2 million acres of transgenic crops were grown in the U.S. alone in 1999. BIO's estimate of worldwide production of transgenic crops from 1996 to 1998 was 101 million acres. If $80 \%$ of these were in the U.S. - a conservative estimate-then the 1999 production was about $48.5 \%$ of the cumulative pre-1999 US acreage of transgenic crops (see BIO estimates at http://www.bio.org/food\&ag/1999 Acreage.html). It is interesting that the estimation of the total crop acreage under regulated test permits (1987-1999) in the U.S. was approximately 0.4 million acres or only $0.2 \%$ of the total acreage of transgenic crops grown during that period (Doug King, personal communication based on APHIS field permit data at http://www.isb.vt.edu).

If we assume that approximately 16000 individual plants are grown per acre (a conservative estimate for field corn), then since 1987, approximately 2.5 trillion transgenic plants have been grown in the field in the U.S. during the past dozen years (approximately 3.5 
trillion plants counting 2000 estimates from USDA)! There is no indication today that this technology has resulted in environmental hazards or compromised human health.

Plant biotechnology offers tremendous promise for feeding the world's growing population and also for improving the diets of people around the world. Although concerns for ecological and human health safety have led to mistrust over the application of this technology, many of these fears seem unsubstantiated or based on misinformation. A concerted effort must be made to identify valid concerns and risks, and to provide reliable and useful information to the public.

Let us not confuse the previous statement with spreading vast quantities of data. Scientists need to serve as the source of accessible information to demystify GM crops and foods. Previously, GM foods have focused on increased yield and other agronomic properties, which primarily benefit agribusiness corporations and farmers. The second generation of GM foods will emphasize consumer health benefits. It is only with these new crops that the public will come to accept the uses of genetic modification of foods, and it is here that the overlap of nutritional science, ecology and plant biotechnology will become most evident. In addition, biotechnologists need the participation of ecological researchers and nutritionists to better determine the biosafety of transgenic plants.

In general, scientists must become more proactive in the public debate if agricultural biotechnology is to make a long-lasting and sustainable impact on improving food and fiber production and human health. Currently, environmental groups have been the most vocal in the debate over GM crops. Their arguments have primarily been based on fear of the unknown and technology, plus misinformation that is based on the misrepresentation of scientific data. Because of its obvious financial stake in the outcome, the agricultural biotechnology industry's position is precarious when its opinion in the public forum is being sought.

Academic and public scientists have tended to make two mistakes with regard to the current controversy. The first is their reticence to speak directly to the public and the media for fear of being misunderstood. The second is their assumption that the public and the media will take their scientific data at face value. However, media sensationalism of single experiments can lead public opinion to make misinformed decisions. These mistakes have effectively removed the most objective and dispassionate parties (scientists) from the debate, which is unfortunate for public policy. For a scientific and technical society such as ours to function properly, public policy must be formed and shaped by the ideas of those who understand the science and technology best.

Scientists need to reexamine their role and professions to include more public and media outreach as part of their everyday work. Failure to do so will exacerbate the misunderstanding and fear surrounding the current controversy and those that will follow. This controversy is complex, and good science and communication of science are not silver bullets. As scientists, we must do our part.

\section{ACKNOWLEDGMENTS}

We would like to thank Reggie Millwood for his assistance and for funding from the USDA Biotechnology Risk Assessment grant no. 9804086.

\section{REFERENCES}

1.Adler, K.S., K. Wikler, F.S. Wyndham, C.R. Linder and J. Schmitt. 1993. Potential for persistence of genes escaped from canola: germination cues in crop, wild and crop-wild hybrid Brassica rapa. Funct. Ecol. 7:736-745.

2.Astwood, J.D., J.N. Leach and R.L. Fuchs. 1996. Stability of food allergens to digestion. Nat. Biotechnol. 14:1269-1273.

3.Bechtold, N., J. Ellis and G. Pelletier. 1993. In planta Agrobacteriummediated gene transfer by infiltration of adult Arabidopsis thaliana plants. C.R. Acad. Sci. Paris 316:1194-1199.

4.Beetham, P.R., P.B. Kipp, X.L. Sawycky, C.J. Arntzen and G.D. May. 1999. A tool for functional plant genomics: chimeric RNA/ DNA oligonucleotides cause in vivo gene-specific mutations. Proc. Natl. Acad. Sci. USA 96:8774-8778

5.Beringer, J.E. 1999. Cautionary tale on safety of GM crops. Nature 399:405.

6.Christou, P. and D.E. McCabe. 1992. Prediction of germ-line transformation events in chimeric $\mathrm{R}_{\mathrm{O}}$ transgenic soybean plantlets us- ing tissue-specific expression patterns. Plant J. 2:283-290.

7.Clough, S.J. and A.F. Bent. 1998. A simplified method for Agrobacteriummediated transformation of Arabidopsis thaliana. Plant J. 16:735-743.

8.Cole-Strauss, A., K. Yoon, Y.B.B.C. Xiang, M.C. Rice, J. Gryn, W.K. Holloman and E.B. Kmiec. 1996. Correction of the mutation responsible for sickle cell anemia by an RNA/DNA oligonucleotide. Science 273: 1386-1389.

9.Conner, A.J. and J.M.E. Jacobs. 1999. Genetic engineering of crops as potential source of genetic hazard in human diet. Mutat. Res. 443:223-234.

10.Ellstrand, N.C., S.C. Hand and J.F. Hancock. 1999. Gene flow and introgression from domesticated plants into their wild relatives. Ann. Rev. Ecol. Syst. 30:539-563.

11.Ewen, S.W.B. and A. Pusztai. 1999. Effects of diets containing genetically modified potatoes expressing Galanthus nivalis lectin on rat small intestines. Lancet 354:1353-1355.

12.FAO/WHO Expert Consultation on Foods Derived from Biotechnology. 2000. Safety Aspects of Genetically Modified Foods of Plant Origin, p. 37. World Health Organization, Geneva, Switzerland.

13.Finer, J.J., K.R. Finer and T. Ponappa. 1999. Particle bombardment mediated transformation, p. 60-80. In J. Hammond, P. McGarvey and V. Yusibov, (Eds.). Plant Biotechnology: New Products and Application. Springer-Verlag, Heidelberg, Germany.

14.Frank-Oberaspach, S.L. and B. Keler. 1997. Consequences of classical and biotechnological resistance breeding for food toxicology and allergenicity. Plant Breed. 116:1-17.

15.Gendel, S.M. 1998. Sequence databases for assessing the potential allergenicity of proteins used in transgenic foods. Adv. Food Nutr. Res. 42:63-92.

16. Ghorbel, R., J. Juarez, L. Navarro and L. Pena. 1999. Green fluorescent protein as a screenable marker to increase the efficiency of generating transgenic woody fruit plants. Theor. Appl. Genet. 99:350-358.

17.Gianessi, L.P. and J.E. Carpenter. 1999. Agricultural Biotechnology: Insect Control Benefits. National Center for Food and Agricultural Policy, Washington, DC.

18.Goto, F., T. Yoshihara, N. Shigemoto, S. Toki and F. Takaiwa. 1999. Iron fortification in rice seed by the soybean ferritin gene. Nat. Biotechnol. 17:282-286.

19.Hammond, B.G., J.L. Vicini, G.F. Hartnell, M.W. Naylor, C.D. Knight, E.H. Robinson, R.L. Fuchs and S.R. Padgette. 1996. The feeding value of soybeans fed to rats, chickens, catfish, and dairy cattle is not altered by genetic incorporation of glyphosate tolerance. J. Nutr. 126:717-727.

20.Hansen, G. and M.-D. Chilton. 1999 Lessons in gene transfer to plants by a gifted microbe, p. 22-55. In J. Hammond, P. McGarvey and V. Yusibov, (Eds.). Plant Biotechnology: New Products and Applications. Springer-Verlag, Heidelberg, Germany.

21.Hansen, G. and M.S. Wright. 1999. Recent advances in the transformation of plants. Trends Plant Sci. 4:226-231. 
22.Harrison, L.A., M.R. Bailey, M.W. Naylor, J.E. Ream, B.G. Hammond, D.B. Nida, B.L. Burnette, T.E. Nickson et al. 1996. The expressed protein in glyphosate-tolerant soybean, 5-enolpyruvyl-shikimate-3-phosphate synthase from Agrobacterium sp. CP4, is rapidly digested in vitro and is not toxic to acutely gavaged mice. J. Nutr. 126:728-740.

23.Hashimoto, W., K. Momma, H.J. Yoon, S. Ozawa, Y. Ohkawa, T. Ishige, M. Kito, S. Utsumi and K. Murata. 1999. Safety assessment of transgenic potatoes with soybean glycinin by feeding studies in rats. Biosci. Biotech. Biochem. 63:1942-1946.

24.Hauser, T., R.G. Shaw and H. Ostergard. 1998. Fitness of $F_{1}$ hybrids between weedy Brassica rapa and oilseed rape (B. napus). Heredity 81:429-435.

25.Hauser, T., R. Jorgensen and H. Ostergard. 1998. Fitness of backcross and $F_{2}$ hybrids between weedy Brassica rapa and oilseed rape (B. napus). Heredity 81:436-443.

26.Hilbeck, A., M. Baumgartner, P.M. Fried and F. Bigler. 1998. Effects of transgenic Bacillus thuringiensis corn-fed prey on mortality and development time of immature Chrysoperla carnea (Neuroptera: Chrysopidae). Environ. Entomol. 27:480-487.

27.Hodgson, J. 1999. Monarch Bt-corn paper questioned. Nat. Biotechnol. 17:627.

28.Horsch, R.B., J.E. Fry, N.L. Hoffman, D. Eichholtz, S.G. Rogers and R.T. Fraley. 1985. A simple and general method for transferring genes into plants. Science 227:12291231.

29.Jefferson, R.A. 1988. Assaying chimeric genes in plants: the GUS gene fusion system. Plant Mol. Biol. Rep. 5:387-405.

30.Joersbo, M., S.G. Petersen and F.T. Okkels. 2000. Parameters interacting with mannose selection employed for the production of transgenic sugar beet. Physiol. Plant 105:109115 .

31.Jones, L., O. Voinnet, C.L. Thomas, A.J. Maule and D.C. Baulcombe. 1999. RNADNA interactions and DNA methylation in post-transcriptional gene silencing. Plant Cell 11:2291-2301

32.Jorgensen, R.B., T. Hauser, T.R. Mikkelsen and H. Ostergard. 1996. Transfer of engineered genes from crop to wild plants. Trends Plant Sci. 1:356-358.

33.Klein, T.M., E.D. Wolf, R. Wu and J.C. Sanford. 1987. High-velocity microprojectiles for delivering nucleic acids into living cells. Nature 327:70-73.

34.Klein, T.M., M. Fromm, A. Weissinger, W. Tomes, S. Schaaf, M. Slettin and J. Sanford. 1988. Transfer of foreign genes into intact plant cells with high-velocity microprojectiles. Proc. Natl. Acad. Sci. USA 85:43054309.

35.Kohli, A., M. Leech, P. Vain, D.A. Laurie and P. Christou. 1998. Transgene organization in rice engineered supports a two-phase integration mechanism mediated by the establishment of integration hot spots. Proc. Natl. Acad. Sci. USA 95:7203-7208.

36.Krysan, P.J., J.C. Young and M.R. Sussman. 1999. T-DNA as an insertion mutagen in arabidopsis. Plant Cell 11:2283-2290.

37.Kuiper, H.A., P.J.M. Noteborn and A.C.M.
Peinenburg. 1999. Adequacy of methods for testing safety of genetically modified foods. Lancet 354:553-564

38. Kunkel, T., Q.W. Niu, Y.-S. Chan and N.-H. Chua. 1999. Inducible isopentenyl transferase as a high-efficiency marker for plant transformation. Nat. Biotechnol. 17:916-919.

39.Leffel, S.M., S.A. Mabon and C.N. Stewart, Jr. 1997. Applications of green fluorescent protein in plants. BioTechniques 23:912-918.

40.Lehrer, S.B., W.E. Horner and G. Reece. 1996. Why are some proteins allergenic? Crit. Rev. Food Sci. Nutr. 36:553-564.

41.Linder, C.R. 1998. Potential persistance of transgenes: seed performance of transgenic canola and wild 'canola hybrids. Ecol. Appl. 8:1180-1195.

42.Losey, J.E., L.S. Rayor and M.E. Carter. 1999. Transgenic pollen harms monarch larvae. Nature 399:214

43.Lucy, A.P., H.-S. Guo, W.-X. Li and S.-W. Ding. 2000. Suppression of post-transcriptional gene silencing by a plant viral protein localized in the nucleus. EMBO J. 19:16721680.

44.McCabe, D.E., W.F. Swain, B.J. Martinell and P. Christou. 1988. Stable transformation of soybean (Glycine max) by particle acceleration. Bio/Technology 6:923-926.

45.Mendieta, N.L.R., A.M. Nagy and F.A. Lints. 1997. The potential allergenicity of novel foods. J. Food Sci. Agric. 75:405-411.

46.Metz, P.L.J., E. Jacobsen, J.-P. Nap, A. Pereira and W.J. Stiekema. 1997. The im pact of biosafety of the phosphinothricin-tolerance transgene in inter-specific $B$. rapa $^{\prime} B$. napus hybrids and their successive backcrosses. Theor. Appl. Genet. 95:442-450.

47.Mikkelsen, T.R., B. Andersen and R.B. Jorgensen. 1996. The risk of crop transgene spread. Nature $380: 31$

48.Niiler, E. 1999. GM corn poses little threat to monarch. Nat. Biotechnol. 17:1154.

49.Nordlee, J.A., S.T. Taylor, J.A. Townsend, L.A. Thomas and R.K. Bush. 1996. Identification of a Brazil-nut allergen in transgenic soybean. N. Engl. J. Med. 334:688-692.

50.Palm, C.J., K. Donegan, D. Harris and R.J. Seidler. 1994. Quantification in soil of Bacillus thuringiensis var. kurstaki delta-endotoxin from transgenic plants. Mol. Ecol. 3:141-151.

51.Palm, C.J., D.L. Schaller, K. Donegan and R.J. Seidler. 1996. Persistence in soil of transgenic plant produced Bacillus thuringiensis var. kurstaki delta-endotoxin. Can. J. Microbiol. 42:1258-1262.

52.Pawlowski, W.P. and D.A. Somers. 1998. Transgenic DNA integration into the oat genome is frequently interspersed by host DNA. Proc. Natl. Acad. Sci. USA 95:1210612110.

53. Raybould, A.F. and A.J. Gray. 1993. Genetically modified crops and hybridization with wild relatives: a UK perspective. J. Appl. Ecol. 30:199-219.

54.Regal, P.J. 1994. Scientific principles for ecologically based risk assessment of transgenic organisms. Mol. Ecol. 3:5-13.

55.Saxena, D., S. Flores and G. Stotzky. 1999 Insecticidal toxin in root exudates from $B t$ corn. Nature 402:480.

56.Scheffler, J.A. and P.J. Dale. 1994. Opportu- nities for gene transfer from transgenic oilseed rape (Brassica napus) to related species. Transgenic Res. 3:263-278

57.Schuler, T.H., R.P.J. Potting, I. Denholm and G.M. Poppy. 1999. Parasitoid behavior and $B t$ plants. Nature 400:825-826.

58.Shelton, A.M., J.D. Tang, R.T. Roush, T.D. Metz and E.D. Earle. 2000. Field tests on managing resistance to $B t$-engineered plants. Nat. Biotechnol. 18:339-342.

59.Sims, S.R. and L.R. Holden. 1996. Insect bioassay for determining soil degradation of Bacillus thuringiensis subsp. kurstaki CryIA(b) protein in corn tissue. Environ. Entomol. 25:659-664.

60.Stewart, C.N., Jr., J.N. All, P.L. Raymer and S. Ramachandran. 1997. Increased fitness of transgenic insecticidal rapeseed under insect selection pressure. Mol. Ecol. 6:773779 .

61.Tabashnik, B.E. 1994. Evolution of resistance to Bacillus thuringiensis. Ann. Rev. Entomol. 39:47-79.

62.Tabashnik, B.E., Y.-B. Liu, N. Finson and L. Masson. 1997. One gene in diamondback moth confers resistance to four Bacillus thuringiensis toxins. Proc. Natl. Acad. Sci. USA 94:1640-1644.

63.Voinnet, O., Y.M. Pinto and D.C. Baulcombe. 1999. Supression of gene silencing: a general strategy used by diverse DNA and RNA viruses of plants. Proc. Natl. Acad. Sci. USA 96:14147-14152.

64.Warwick, S.I., H.J. Beckie and E. Small. 1999. Transgenic crops: new weed problems for Canada? Phytoprotection 80:71-84.

65.Waterhouse, P.M., N.A. Smith and M.B. Wang. 1999. Virus resistance and gene silencing: killing the messenger. Trends Plant Sci. 4:452-457.

66. Weisser P., R. Kramer and G.A. Sprenger. 1996. Expression of the Escherichia coli pmi gene, encoding phosphomannose isomerase in Zymomonas mobilis, leads to utilization of mannose as a novel growth substrate. Appl. Environ. Microbiol. 62:4155-4161.

67.Wraight, C.L., A.R. Zangerl, M.J. Carroll and M.R. Berenbaum. 2000. Absence of toxicity of Bacillus thuringiensis pollen to black swallowtails under field conditions. Proc. Natl. Acad. Sci. USA 97:7700-7703.

68. Ye, X., A. Al-Babili, A. Kloti, J. Zhang, P. Lucca, P. Beyer and I. Potrykus. 2000. A (b -carotene) biosynthetic pathway into (carotene-free) rice endosperm. Science 287: 303-305.

69.Zhu, T., D.J. Peterson, L. Tagliani, G. St. Clair, C.L. Baszczynski and B. Bowen. 1999. Targeted manipulation of maize genes in vivo using chimeric RNA/DNA oligonucleotides. Proc. Natl. Acad. Sci. USA 96: 8768-8773.

Address correspondence to:

Dr. Neal Stewart, Jr.

Department of Biology

University of North Carolina

Greensboro, NC 27402-6174, USA

e-mail:nstewart@uncg.edu 